\title{
Medical geography \\ and phthisic immunity in the high altitudes : \\ The origins of a Therapeutic hypothesis
}

\section{Daniela Vaj}

Researcher FNS/PNR 48, Historian

vaj.daniela@geneva-link.ch

\begin{abstract}
Medical geography expanded considerably in the $19^{\text {th }}$ century. Its expansion was aided by a Neo-Hippocratic trend in medical thinking, progress in statistics and hygiene, and an overall vision of geography formulated early in the century by French and German geographers inspired by Alexander von Humboldt. By tracing out the process that prompted certain
\end{abstract}

" doctor-geographers » to put forth the hypothesis of immunity phthisis in elevated regions, this article seeks to show how various trends in medical geography led to the establishment of the " altitude cure " as a treatment for tuberculosis.

Keywords : Medical geography, history of medicine, medical cartography, climatotherapy, tuberculosis, altitude.

\section{Climate Tourism in the Alps in the $19^{\text {th }}$ Century}

High-altitude climate tourism in the Alps began expanding considerably in the latter half of the $19^{\text {th }}$ century. The fortunes of many major Alpine resorts was closely linked to the medical instrumentalisation of the climate, and their histories often emphasize the roles played by doctors who launched the idea of the altitude cure. Historians look to the experiments conducted by Hermann Brehmer for the origins of climate tourism in the Alps : in 1859 , he opened the first climatic institute for the treatment of tuberculosis. This first sanatorial undertaking is often connected to a visit Brehmer made to the Himalayas, during which he was apparently cured of a form of tuberculosis. Upon return, he sought to reproduce the climatic cure associated with a specific altitude in Görbersdorf in Silesia (557 m, LN 50 51'). The altitude cure was to then spread rapidly to many alpine locales. This version of the facts appeared in the post-war years, when the effectiveness of streptomycin therapies marked the decline of the climatic treatment of tuberculosis. However, this version raises many doubts, since the documents of the period do not mention Brehmer's supposed visit to India. No matter : if it is a legend, it has its own charm, as well, especially as its own meaning. It was indeed in India, in the beginning of the $19^{\text {th }}$ century, that the first high-altitude resorts appeared that were intended for the easing of various illnesses - in this case, associated with the tropical climates. The pioneering and audacious "Brehmer Myth" is only of interest to the extent that the idea of treating tuberculosis with the altitude cure is bound up in a precise scientific context : one that was favourable to the study of mountain climates. That context concretized the possibility of using Alpine air for therapeutic ends. To be more specific, the altitude cure came about due to the contributions of many doctors and experts around the globe. By studying period sources, I have managed to reconstitute the process that enabled the formulation of this therapeutic hypothesis. 
In chronological terms, the hypothesis of phthisic immunity in high altitude regions developed over three phases. The initial, " emergent " phase consisted of writings that indicated the absence of phthisis in certain elevated areas and formulated the first explanatory hypotheses. This phase extended from the first decades of the $19^{\text {th }}$ century to about the $1850 \mathrm{~s}$ when the first institution for the treatment of tuberculosis according the immunity hypothesis was opened. The second phase was one of " consolidation " and is characterised by the proliferation of studies and inquiries into the question, as well as by the appearance of the first high-altitude resorts dedicated to the treatment of tuberculosis. This period extended from the 1860 s to the last decades of the $19^{\text {th }}$ century, when the tuberculosis bacillus was discovered. The third, "stabilisation" phase, saw the idea of absolute or relative " immunity " abandoned, in favour of the more general notion of the preventive and treatment-oriented virtues of higher-elevation climates with respect to certain forms of tuberculosis. It was during this phase that the high-altitude sanatoria multiplied in number. The third phase covers the first half of the $20^{\text {th }}$ century, ending in the first years of the post-war era. In the pages that follow, I illustrate the first of these phases through the use of five works of medical geography. This was the field of study that gave rise to the hypothesis of the phthisic immunity of the high altitudes. My study is based on the analysis of a very large corpus of sources since, to my knowledge, no contemporary work has approached the question of the ties between medical geography and the climatic treatment of tuberculosis from an historical point of view.

\section{The Rise of Medical Geography}

The rapid expansion of medical geography in the $19^{\text {th }}$ century went unabated until the arrival of bacteriology at century's end (Barrett 2000, Rupke 2000). Studies in this realm were fuelled by Neo-Hippocraticism, which came to the fore in the second half of the $18^{\text {th }}$ century and gave great importance the study of man's relationship to his environment. However, medical geography has a long history that most of its adepts refer to. The earliest study that can be associated with that history comes from Hippocrates. In On Airs, Waters, and Places, a book that was to be immensely influential over the centuries, the doctor from Cos demonstrates the effect of climate on illness. While the Middle Ages contributed little to medical geography, the Renaissance returned to the study of the natural world and took its geographical diversity into account. The era of great discoveries saw its doctors take an interest in the illnesses of distant populations. Yet it was primarily in the $18^{\text {th }}$ century that a new genre appeared : in the latter half of the century, the first medical topographies were created and disseminated. On the strength of the progress made in physical geography, medical geography in the $19^{\text {th }}$ century sought to go beyond the descriptive character of its topographies and become an explanatory science. Hence, several doctors attempted to formulate rules for understanding the geographical distribution of illnesses, and established causal relationships between milieus and patho-physiological phenomena.

Their efforts followed several different slants in the $19^{\text {th }}$ century. One very pragmatic approach focused primarily on the idea of the tropical milieu, and was very closely linked to colonial expansion. Other, more theoretical ones hinged on the overall vision of geogra- 
phy formulated by Alexander von Humboldt, Karl Ritter and Conrad Malte-Brun at century's outset. Though equally interested in climatological and bio-geographical studies, doctors like August Hirsch, Jean-Christian-Marc Boudin and Henri Clermond Lombard stand out from the others by their substantial use of statistical data and the importance they gave to public hygiene and to the study of the historical evolution of illnesses. Still others, like Adolf Mühry and Caspar Friedrich Fuchs borrowed their methods from physical geography. These doctors were the first to advance their own theory of altitude as an explanatory principle. They took up Humboldt's programme and integrated the systematic, global study of the different illness into it, using representational forms borrowed from the new geography of plants (Rupke 1996). One should recall that it was in 1805 that Humboldt published his foundational work, which brings together the results of his research into plant distribution and explores the relationship between climates and plant species. His study divides plant life into zones, as a function of altitude and latitude, by examining its relationships to landscape, light, air, and to geological and geomorphologic elements. $\mathrm{He}$ demonstrates that landscape is structured according to an altitudinal gradient, thus showing the essential role of altitude in the distribution of vegetation. Humboldt then integrates altitude into his study of the vegetal zones of different latitudes, showing that the distribution of vegetation functions according to sum of the physical factors of each of the world's climates (fig. 1). With an eye toward the aesthetic in addition to the scientific, Humboldt gives himself the task of " grasping the world of phenomena and physical forces in their complexity and mutual influences". This fundamental ambition would mark many disciplines, including that of medical geography. Humboldt's influence is manifest in a number of the studies on the phthisic immunity of the high altitudes conducted in the first phase of that concept's development. In addition, Humboldt himself had pointed out the absence of phthisis in certain elevated regions, during his trip to the equinoctial areas. Furthermore, it is because of Humboldt's intervention that Brehmer was able to count on the support of Johann Lukas Schönlein, famous personal doctor to King Frederick William IV, when Brehmer applied for authorisation to open his curative establishment. Indeed, Humboldt had been one of the few, appreciative readers of Brehmer's work when it was published in 1857, as witnessed to by these lines Humboldt wrote to him on June 26, 1857 :

"You were able to describe from the perspective of geography and natural history how the composition of the ground, the air, and style of life influence the pathological states as well as the interactions of so many forces to be given account of in complex organisms. Your work, which I had the pleasure of pointing out to my learned friend Schönlein, has the additional quality - rare today in medical writings - of a charming clarity of exposition and description. » (Brehmer 1869)

\section{The Construction of a Therapeutic Hypothesis}

The idea of the phthisic immunity of the higher altitudes hinged on an essentially empirical foundation : local populations considered mountain air healthy. It was the work of Pastor Louis Muret in 1764 that made it possible for a scientist like Malthus to refer to the longe- 
vity of the inhabitants of Leysin - a village in the Alps in the Vaud canton. Horace-Bénédicte de Saussure noticed in his travels that it was customary among the wealthy inhabitants of the Wallis region to have their wives give birth and raise their children in the mountains. He also noted that cretinism disappeared above 1000 metres. Beginning in 1828, Dr. Bezencenet recommended that children suffering from cretinism undergo a cure in the climate of Leysin. In 1840 a Genevan doctor, Louis-André Gosse, recommended visits in the higher elevations as a preventative against cretinism and Johan Jacob Guggenbühl, a year later, opened his establishment for cretinous children in Adendberg in the Bernese Alps. For over a dozen years, he enjoyed an international reputation (Ruchat 2000). However the mountain climate was not considered an effective remedy in the fight against cretinism alone. Dr. Lucius Ruëdi pointed out its beneficent effects on children afflicted with tuberculosis, which he began treating in Davos in 1841. In India, Robert Baikie remarked in his study on the Nilgiri Hills that early-stage tuberculosis could easily be treated at their altitudes (Baikie 1834). The custom of going to mountains in the Andes to treat tuberculosis was a widespread practice among inhabitants of the lowland regions of Peru.

Based on these kinds of practices, as well the first medical statistics, accounts by travelling scientists, and their own observations, doctors like Archibald Smith (Smith 1840), began to take an interest in this question. Smith, a Scottish doctor, had spent seven years in Peru. He had practiced mostly in Lima, but had visited the country and gathered interesting information on the state of health of the country. In 1840, he published an article on the phthisis that had struck the Peruvian coast and Lima in particular. Smith noted that the ill from these areas would find comfort in, and even healing from visits to sites located between five and ten thousand feet. In Peru, he reminds us, the climate of the elevated regions was taken as unmatched in treating haemoptysis. Having spent a year in the mining city of Cerro de Pasco, he remarks the absence of phthisis and points out that the Indians seem quite acclimated to high-altitude : their ribcages and lungs were especially well-developed, due to the rarefied air.

Some years later, and upon his return to Europe after five years in Peru, Johann Jacob von Tschudi published a remarkable work on the geography of illnesses in that country (Tschudi 1846). In it, the doctor and naturalist from Neuchâtel divides Peru into five regions according to altitude and geomorphological criteria : the coastal region of Lima, the Western Sierra, the Puna region, the Eastern Sierra, and the forest region. He analyzes each region according to several aspects of medical geography, including illnesses, caregiving sites, medical practices, hygiene and nourishment. For Tschudi, the very different climatic conditions of these regions result in families of dominant illnesses. His study of their geographical localisation underscores the rarity of certain ones among them in specific areas. Thus, for instance, he notes the high frequency of tuberculosis in the coastal region and, like Smith, observes that Peruvian doctors customarily send phthisic patients to the higher Puna region.

While work on the subject began to be appear in Latin American medical publishing, it was the work of Smith and Tschudi, published in the well-distributed journals in Europe, that had the greatest repercussions on the whole of the scientific community. 
Fuchs' work is of particular importance to the argument here. A practitioner from Brotterode, a small village in the Thuringian Forest, Fuchs had a keen interest in the study of medical geography. After an initial study of medical topography devoted to his region, and article on the influence of verticality on the distribution of illnesses, he published a book in 1853 that attempted to establish the laws that explain the distribution of illnesses in the world. His analysis is based on a three-dimensional model that uses the parameters of latitude, longitude and altitude to circumscribe zones made up of specific types of illness. The importance of these three variables is explicitly demonstrated in the numerous illustrations throughout the book, certain of which are copies of illustrations by Humboldt and Berghaus (fig. 2). Fuchs' book marks an important moment in the history of medical cartography. In it, he identifies three regions according to the most widespread diseases : the dysenteric, enteromesenteric, and catarrhic regions, their borders vary as a function of the variables of altitude, longitude and latitude, as shown in the example reproduced here (fig. 3). The region in this example is characterised by a strong presence of abdominal typhus and phthisis, as well as scrofulous diseases, cancers and meningitis. Fuchs' analysis focuses mostly on the distribution of phthisis, and is based on studies conducted in the Alps, Thuringia, the Hartz mountain chain, and the American continent. He determines that tuberculosis is most widespread at sea-level and diminishes in frequency at higher altitudes and more northern latitudes, disappearing in the catarrhic region, which is just above the snowline and shows the strong presence of respiratory diseases like bronchitis, pneumonia, emphysema, etc. Fuchs' study attempts to shed light on altitude's therapeutic possibilities in a chapter on the issue of moving the sick in order to heal them. To limit blood pressure in the lungs, Fuchs recommends that patients suffering from phthisis stay in elevated zones where transpiration and respiration are easier. Indeed, the atmospheric pressure is lesser in those areas and, for Fuchs, this plays an important role in the aetiology of pulmonary diseases and even has an influence on human behaviour. He is very critical of the traditional practice of sending phthisis patients to Southern European countries, most of which fall within either the enteromesenteric zone, in which disease is very widespread, or the very unhealthy dysenteric zone. For Fuchs, treatment must occur in areas where phthisis does not occur ; namely, the catarrhic region. While his study may strike us today as a rather naïve generalisation, it does nonetheless constitute the first attempt at theorising the unique advantages of high-altitude climates for the purpose of treating tuberculosis.

The fundamental work of another German must also be taken into account as regards the « emergent » phase. Adolf Mühry was a doctor-geographer who was close to Humboldt's work ; Mühry's 1856 treatise was dedicated to Humboldt. Unlike Fuchs, Mühry had spent time in the major European medical centres and had the University of Göttingen's library collection at his disposal. His work is thus well documented. Comprised of approximately 350 texts, Mühry's writings were meant to produce a synthesis capable of determining the geographical distribution of disease the world over, and to propose a coherent systematics. His approach was that of a theoretician, and was based on the conviction that a global geographic study analysing the distribution of disease could lead to understanding its nature. This would in turn result in a therapeutics based on the considered choice of locations favourable to the treatment of specific afflictions. There are two important underlying 
components of his nosological concept. First, it identifies two categories of disease, miasmatic and contagious, of which only the first depends on geographical factors ; second, it is based on the belief that diseases are essentially static in nature and brought about by geographically distributed factors. One should recall that in the years preceding the publication of Darwin's research, many doctors shared this view. In his work, Mühry acknowledges that diseases undergo modifications prompted by geographical factors ; yet, their stable nature allows for their classification. Thus he builds a model based on temperature tables, from which emanate the laws according to which the diseases are distributed. Mühry establishes four zones, three of which are illustrated in a drawing (fig. 4) and are can be seen in the map that accompanies the book (fig. 5). Mühry's debt to Humboldt is clear : indeed, to show the division of the zones Mühry uses the isothermal lines Humboldt created in 1817 (Humboldt 1817). Mühry distinguishes ubiquitous diseases from those that are concentrated in specific zones and for which the influence of geographical factors seems preponderant. When studying the diseases, he always gives a paragraph to describing those that appear to be absent from certain areas - one such disease is phthisis. He based his ideas on recent studies that also insist on the absence of phthisis from certain elevated regions, and from the Faeroe Islands, Fiji, and the Kirghiz Steppes. In the treatise, the subject is only given passing attention. However, while the treatise was still being printed, Mühry decided it was necessary to address the subject further in an article that was published prior to the book (Mühry 1855). The article is comprised of two parts, the second of which is devoted to the absence of phthisis in elevated regions. Mühry admits that the available data are insufficient to accord his hypothesis the power of a scientific truth. In Europe, there were indeed few inhabited areas of use to such research. The raised plateaux of the tropical zone chains, however, like Mexico or the Andes mountain chain, were inhabited by large populations, but have been the object of few studies thus far. Furthermore, as regards India, where phthisis was not yet endemic, statistical data was simply lacking. Nonetheless, his study made do with the available data. In it, Mühry sets aside the hypothesis that the dryness of air is a factor, since phthisis is rare in India, where the air is very humid. Inversely, phthisis is very frequent in Chile, where the air is very dry. He postulates that the formation of tubercles in the lungs is rendered difficult by the low atmospheric pressure and the rarefaction of oxygen. A chemical hypothesis points to the lower carbon dioxide content, and another - this time, mechanical - hypothesis suggests that the amplitude of respiration provokes the enlargement of the ribcage. Mühry observes that Indians living at high elevations have very spacious thoraxes and more developed lungs. As tubercles form almost exclusively at the tip of the lungs, where their shape is at its most narrow, Mühry considers the enlargement of the lungs induced by adaptation to rarefied air to be the most likely explanation for the rarity of phthisis at high altitudes.

According to Mühry, observations made in the high Andes plateaux can have therapeutic consequences. Patients suffering from phthisis ought, therefore, to seek out the few elevated regions in Europe, especially if the curative stay should include the regular practice of deep breathing. 


\section{Phthisic Immunity and the Momentum of the Altitude Cure}

In the 1850 s, doctors in every country began to take an interest in the question of altitude therapy. In Europe, the idea of phthisic immunity emerged primarily among Swiss doctors. In fact, in the same year as the publication of Mühry's book, Henri-Clermond Lombard published a work devoted entirely to studying mountain climates from a medical point of view (Lombard 1856). Lombard was one of the chief representatives of medical geography throughout the $19^{\text {th }}$ century. His essay attracted considerable interest from the scientific community, and three editions of it were sold. The volume is a synthesis of observations the Genevan collected from his travels. To these he adds his practices, readings, and information culled from scientific collaboration with his Swiss and French colleagues. He presents the climates of elevated regions and analyses various elements of their intricate complexity. His foremost interest is the effects of mountain climates on human physiology, and comes up with a system that divides climates into two classes according to altitude. With a tendency to rather excessive generalisation, Lombard applies his definition of alpine climates to the high Alpine regions as well as the high plateaux of Latin America and the Himalayas. His definition of alpestrine climates applies to the sub alpine and lower regions of the Alps. Lombard uses the correlation between frequency of disease and altitude to analyse the pathologies that can be either weakened or cured by a stay in the mountains. Even though his generalisation seems premature in light of the state of knowledge on the subject at the time, Lombard believed that the benefits of a mountain stay are such that they supersede the risks of negative effects in importance. This is why he devotes the second part of his text to determining which alpine locales are the best suited to therapeutic visits. In studying which pathologies can be prevented or cured by a visit to higher elevations, Lombard places special emphasis on phthisis, the frequency of which seems to him to diminish above a certain altitude that varies from climate to climate. He formulates the hypothesis of the phthisic immunity of high altitudes in a way that supposes a kind of antagonism between emphysema - a common pathology in higher altitudes - and phthisis : an antagonism that he explains by referring to the physiological modifications tied to the functional activity of the outer regions of the body and to the plethora of carbon dioxide that results from insufficient oxygenation. He pursued this hypothesis further in several of his writings, and it would later prompt the first Swiss investigation into tuberculosis, launched in 1863, the principal goal of which was to prove the existence of a link between altitude and phthisis (Vaj 2004).

Lombard's work intersects with research several French doctors conducted in the same period in Latin America. Denis Jourdanet's research, which began to appear in publication in 1861, is of fundamental importance and deserves further attention. He went as far as to determine a law for protecting from phthisis (Jourdanet 1875) (fig. 6). All of these studies helped fuel interest among those in medicine in elevated climates. Many practitioners began to travel to mountain resorts and observe ; others who were more theoretically oriented, conducted experimental research in order to clarify the physiological effects of high altitude (Barras 2000). Their results led to publications in which the phthisic immunity of the higher altitudes was a recurrent theme - this was the second phase of the construction the therapeutic hypothesis. 
There is no doubt that the cliché of the Alpine landscape as regenerative that was characteristic of Romantic culture laid part of the groundwork for the favourable reception of certain aspects of the debate : the hypothesis of phthisic immunity helped consolidate the Alpine myth (Dagognet 1959). From then on, the idea of Alpine air as a therapeutic agent always found its place in medical guidebooks. More and more practitioners advised their ill patients to go to the mountains, where other doctors adopted a more empirical approach and applied the practice - in existence for some time - henceforth known as " the altitude cure ». The structures backing the cure were medicalised very quickly and became specialised, to the point of supporting the construction of immense sanatoriums and high-altitude climate villages in the third phase of the process. Even though the hypothesis of the immunising power of the high mountains had not been proven by science, it was a seductive and motivating one. The altitude cure turned out to be empirically effective, and the notion of mountain spaces as favourable to health rooted itself in the collective imaginary, doubtlessly contributing to the good fortunes of alpine climate tourism.

\section{References :}

Primary Sources:

BAIKIE R., 1834. - Observations on the Neilgherries, including an account of their topography, climate, soil \& productions, Smoult, William Hunter.

BREHMER H., 1869. - Die chronische Lungenschwindsucht und Tuberkulose der Lunge : ihre Ursache und Ihre Heilung, $2^{\mathrm{e}}$ éd., T.C.F. Enslin.

DAGOGNET F., 1959. - «La cure d'air : essai sur l'histoire d'une idée en thérapeutique médicale ». Thalès, $\mathrm{n}^{\circ} 10$, pp. 75-96.

FUCHS C. F., 1853. - Medizinische Geographie, Alexander Duncker.

HUMBOLDT A. VON et BONPLAND A., 1805. - Essai sur la géographie des plantes, accompagné d'un tableau physique des régions équinoxiales, F. Schoell.

HumbOLDT A., 1817. - "Sur les lignes isothermes ». Annales de chimie et de physique, $\mathrm{n}^{\circ}$ 5, pp. 102-111.

JOURDANET D., 1875. - Influence de la pression de l'air sur la vie de l'homme. Climats d'altitude et climats de montagne, 2 vol., Masson.

LOMBARD H. C., 1856. - « Des climats de montagne considérés au point de vue médical ». Bibliothèque Universelle, Archives des sciences physiques et naturelles, t. XXXII, pp. 265-305 et t. XXXIII, pp. 16-42.

MÜHry A., 1855. - «Uber die Absenz des Phthisis auf einigen Arealen und in des rarificirten Luft hober Regionen ». Zeitschrift für rationelle Medicin, n 7, pp. 365-379. 
MÜHRY A., 1856. - Die geographischen Verhältnisse der Krankheiten, oder Grundzüge der Nosogeographie, éd. Winter'sche Verlaghandlung.

SMITH A., 1840. - " Pratical observations on the Deseases of Peru described as they occur on the Cost and in the Sierra ». Edinburgh Medical and Surgical Journal, vol. LIV, n ${ }^{\circ} 144$, pp. 1-19.

TSCHUDI J. J. von, 1846. - «Ueber die geographische Verbreitung des Krankheiten in Peru ". Oesterreichische medicinische Wochenschrift, n ${ }^{\circ} 12$, pp. 374-380 ; $\mathrm{n}^{\circ} 13,408-414$; $\mathrm{n}^{\circ} 14,438-446 ; \mathrm{n}^{\circ} 15468-476 ; \mathrm{n}^{\circ} 16,506-508 ; \mathrm{n}^{\circ} 18,531-540 ; \mathrm{n}^{\circ} 19,564-572$; $n^{\circ} 20,595-604 ; n^{\circ} 21,630-636 ; n^{\circ} 22,660-668, n^{\circ} 23,694-700, n^{\circ} 24,726-732$.

Secondary sources:

BARRAS V., 2000. - " Physiologie et thérapeutique alpines au tournant du XXe siècle ». J.-C. Pont et J. Lacki (dir.), Une cordée originale, Georg, pp. 219-233.

BARRETT F. A., 2000. - Disease and Geography, the history of an Idea, Geographical Monographs, York University - Atkinson College.

RUCHAT M., 2000. - « Johan Jacob Guggenbühl, les crétins et la montagne sainte (18401856) ». J.-C. Pont et J. Lacki (dir.), Une cordée originale, Georg, pp. 250-264.

RUPKE N. A., 1996. - « Humboldtian medicine ». Medical History, n 40, pp. 293-310.

Rupke N. A. (Ed.), 2000. - Medical Geography in Historical Perspective, Medical History Supplement $n^{\circ} 20$, The Wellcome Trust Center for History of Medicine at UCL.

VAJ D., 2004. - «Le docteur Henri-Clermond Lombard et la naissance de la cure d'altitude ». Revue du praticien, 2004, 14, pp. 1848-1853. 